\title{
HYDROGEN-BOND INDUCED SYNTHESIS, CHARACTERIZATION, AND CRYSTAL STRUCTURES OF END- TO-END AZIDO-BRIDGED POLYMERIC COPPER(II) COMPLEXES DERIVED FROM TRIDENTATE SCHIFF BASES
}

\author{
SHAO-SONG QIAN ${ }^{1}$, XIAO-SHAN CHENG ${ }^{2}$, ZHONG-LU YOU ${ }^{2, *}$, HAI-LIANG ZHUU, * \\ ${ }^{1}$ School of Life Sciences, Shandong University of Technology, ZiBo 255049, P. R. China \\ ${ }^{2}$ Department of Chemistry and Chemical Engineering, Liaoning Normal University, Dalian 116029, P. R. China
}

(Received: January 8, 2013 - Accepted: March 27, 2013)

\begin{abstract}
Two new end-to-end azido-bridged polymeric copper(II) complexes, $\left[\mathrm{CuL}^{1}\left(\mu_{1,3}-\mathrm{N}_{3}\right)\right]_{\mathrm{n}}(1)$ and $\left[\mathrm{CuL}^{2}\left(\mu_{1,3}-\mathrm{N}_{3}\right)\right]_{\mathrm{n}}(2)$, where $\mathrm{L}^{1}$ and $\mathrm{L}^{2}$ are the monoanionic form of 5-methoxy-2-[(2-methylaminoethylimino)methyl]phenol and 4-chloro-2-[(3-dimethylaminopropylimino)methyl]phenol, have been prepared and structurally characterized by elemental analysis, IR spectra, and single crystal X-ray determination. Complex (1) crystallizes in the orthorhombic space group $P 2,2,2$, with unit cell dimensions $a=7.6651(9) \AA, b=8.3213(9) \AA, c=20.149(2) \AA, V=1285.2(2) \AA^{3}, Z=4, R_{1}=0.0296$, and $w R_{2}=0.0697$. Complex (2) crystallizes in the orthorhombic space group Pbca, with unit cell dimensions $a=10.353(1) \AA, b=13.069(2) \AA, c=22.265(2) \AA, V=3012.6(7) \AA^{3}, Z=8, R_{1}=0.0400$, and $w R_{2}=$ 0.1014. Each $\mathrm{Cu}$ atom in the complexes is in a square pyramidal coordination, with three donor atoms of the Schiff base ligand and one azido $\mathrm{N}$ atom defining the basal plane, and with another azido $\mathrm{N}$ atom occupying the apical position. The $\mathrm{Cu} \cdots \mathrm{Cu}$ distances are 5.173(2) $\AA$ in (1) and 5.277(2) $\AA$ in (2). Hydrogen bonds can influence the bridging mode of the azide ligand.
\end{abstract}

Keywords: Schiff base; Copper; Polymeric complex; Crystal structure; Azide

\section{INTRODUCTION}

Polymeric structures of complexes with bridging groups are currently attracting much attention for their interesting structures and wide applications ${ }^{1-3}$. Schiff bases derived from salicylaldehyde and its derivatives are a kind of versatile ligands in coordination chemistry. The rational design and construction of polymeric structures of complexes with Schiff bases are of particular interest in coordination and structural chemistry. The preferred way to construct polynuclear complexes is the use of suitable bridging groups, such as $\mathrm{N}_{3}^{-}, \mathrm{NCS}^{-}, \mathrm{N}(\mathrm{CN})_{2}^{-}$, dicarboxylate, 4,4'-bipy, and so on ${ }^{4-7}$. Among the bridging groups, azide ligand has been received particular interest because it is very useful to design extended polynuclear complexes. It can bind up to three metal atoms when acting as a monatomic bridge (end-on, EO) and up to six using the two terminal nitrogen atoms to bridge (end-to-end, EE) (Scheme $1)^{8-10}$. A major obstacle to a more comprehensive study of such azide-based polymeric coordination complexes is the lack of rational synthetic procedures, since with the present state of knowledge it is hardly possible to determine which coordination mode will be adopted by the azide ligand and whether the sought-after alternating chain structure will finally be formed. Hydrogen bonds are known as an important factor for the self-assembly of complexes ${ }^{11-13}$. Our recent research indicated that hydrogen bonds can influence the bridging modes of azide ligands ${ }^{14}$. As a continuation of the work on self-assembly preparation of azido-bridged polymeric complexes, in this paper, two new end-to-end azido-bridged polymeric copper(II) complexes, [CuL $\left.{ }^{1}\left(\mu_{1,3}-\mathrm{N}_{3}\right)\right]$ (1) and $\left[\mathrm{CuL}^{2}\left(\mu_{1,3}-\mathrm{N}_{3}\right)\right]_{\text {, }}$ (2), where $\mathrm{L}^{1}$ and $\mathrm{L}^{2}$ are the monoanionic form of 5 -methoxy-2-[(2-methylaminoethylimino)methyl]phenol ( $\mathrm{HL}^{1}$; Scheme 1$)$ and 4-chloro-2-[(3-dimethylaminopropylimino)methyl]phenol, ( $\mathrm{HL}^{2}$; Scheme 2), were prepared and structurally characterized.
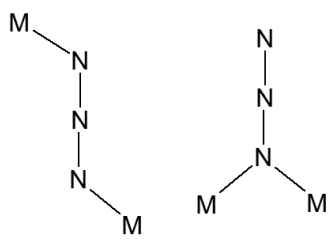<smiles>[M]C([M])N([M])N([M])[M]</smiles><smiles>[M]C([M])N(N)N</smiles>

1,3 (end-to-end)

$1,1($ end-on)
$1,1,3,3$

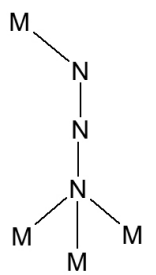

$1,1,1,3$<smiles>CNCC/N=C/c1ccc(OC)cc1O</smiles>

$\mathrm{HL}^{1}$<smiles>CN(C)CCC/N=C/c1cc(Cl)ccc1O</smiles>

$\mathrm{HL}^{2}$
Scheme 2. The Schiff base ligands.

\section{EXPERIMENTAL}

Materials and Methods: Starting materials, reagents and solvents with AR grade were purchased from commercial suppliers and were used without further purification. The Schiff bases were prepared according to the literature method ${ }^{15}$. Elemental analyses were performed on a Perkin-Elmer $240 \mathrm{C}$ elemental analyzer. IR spectra were recorded on a Jasco FT/IR-4000 spectrometer as $\mathrm{KBr}$ pellets in the $4000-200 \mathrm{~cm}^{-1}$ region. Single crystal structural X-ray diffraction was carried out on a Bruker SMART 1000 CCD area diffractometer. Molar conductance of the complexes at concentration of $10^{-3} \mathrm{M}$ in absolute methanol was measured with a Shanghai DDS-11A conductometer. Thermal stability analysis was performed on a Perkin-Elmer Pyris Diamond TG-DTA thermal analyses system.

Synthesis of Complex (1): To the methanolic solution $(10 \mathrm{~mL})$ of $\mathrm{HL}^{1}$ $(0.021 \mathrm{~g}, 0.1 \mathrm{mmol})$ was added a methanolic solution $(10 \mathrm{~mL})$ of copper nitrate $(0.024 \mathrm{~g}, 0.1 \mathrm{mmol})$ and an aqueous solution of sodium azide $(0.007 \mathrm{~g}, 0.1$ $\mathrm{mmol}$ ) with stirring. The mixture was stirred for $30 \mathrm{~min}$ at room temperature to give a blue solution. After keeping the solution in air for a few days, blue block-shaped crystals of the complex, suitable for X-ray crystal structural determination, were formed on slow evaporation of the solvent. The crystals were isolated, washed three times with methanol and dried in air. Yield 53\%. Characteristic IR data $\left(\mathrm{KBr}, \mathrm{cm}^{-1}\right): 3207(\mathrm{~N}-\mathrm{H}), 2036\left(\mathrm{~N}_{3}\right), 1601(\mathrm{C}=\mathrm{N})$. Anal. Calc. for $\mathrm{C}_{11} \mathrm{H}_{15} \mathrm{CuN}_{5} \mathrm{O}_{2}$ : C 42.2, H 4.8, N 22.4\%. Found: C 42.3, H 4.9, N $22.3 \%$.

Synthesis of Complex (2): Complex (2) was prepared by the same method as described for complex (1), but with $\mathrm{HL}^{1}$ replaced with $\mathrm{HL}^{2}(0.024 \mathrm{~g}, 0.1$ mmol). Yield 71\%. Characteristic IR data $\left(\mathrm{KBr}, \mathrm{cm}^{-1}\right): 2045\left(\mathrm{~N}_{3}\right), 1603(\mathrm{C}=\mathrm{N})$. Anal. Calc. for $\mathrm{C}_{12} \mathrm{H}_{16} \mathrm{ClCuN}_{5} \mathrm{O}$ : C 41.7, $\mathrm{H} 4.7, \mathrm{~N} 20.3 \%$. Found: $\mathrm{C} 41.5, \mathrm{H}$ 4.9, N 20.3\%.

Data collection, structural determination and refinement: Diffraction intensities for the complexes were collected at 298(2) K using a Bruker SMART $1000 \mathrm{CCD}$ area-detector diffractometer with $\mathrm{MoK} \alpha$ radiation $(\lambda$ $=0.71073 \AA$ ). The collected data were reduced with the SAINT program ${ }^{16}$, and multi-scan absorption correction was performed using the SADABS 
program ${ }^{17}$. The structures of the complexes were solved by direct method, and were refined against $F^{2}$ by full-matrix least-squares method using SHELXTL ${ }^{18}$. All of the non-hydrogen atoms were refined anisotropically. The amino hydrogen atom of complex (1) was located from a difference Fourier map and refined istropically, with $\mathrm{N}-\mathrm{H}$ distance restrained to $0.90(1) \AA$. The remaining hydrogen atoms were placed in calculated positions and constrained to ride on their parent atoms. The crystallographic data for the complex are summarized in Table 1. Selected bond lengths and angles are given in Table 2.

Table 1 Crystallographic data for the complexes

\begin{tabular}{|c|c|c|}
\hline Compounds & 1 & 2 \\
\hline Empirical formula & $\mathrm{C}_{11} \mathrm{H}_{15} \mathrm{CuN}_{5} \mathrm{O}_{2}$ & $\mathrm{C}_{12} \mathrm{H}_{16} \mathrm{ClCuN}_{5} \mathrm{O}$ \\
\hline Formula weight & 312.8 & 345.3 \\
\hline Temperature/K & $298(2)$ & $298(2)$ \\
\hline Wavelength $/ \AA$ & 0.71073 & 0.71073 \\
\hline Crystal system & Orthorhombic & Orthorhombic \\
\hline Space group & $P 22_{1}{ }_{1} 2_{1}$ & $P b c a$ \\
\hline$a / \AA$ & $7.6651(9)$ & $10.353(1)$ \\
\hline$b / \AA$ & $8.3213(9)$ & $13.069(2)$ \\
\hline$c / \AA$ & $20.149(2)$ & $22.265(2)$ \\
\hline$V / \AA^{3}$ & $1285.2(2)$ & $3012.6(7)$ \\
\hline$Z$ & 4 & 8 \\
\hline$\mu / \mathrm{mm}^{-1}$ & 1.705 & 1.630 \\
\hline$D_{c} / \mathrm{g} \mathrm{cm}^{-3}$ & 1.617 & 1.523 \\
\hline Reflections collected & 7653 & 16226 \\
\hline Unique reflections & 2780 & 3283 \\
\hline $\begin{array}{l}\text { Observed reflections }[I \geq \\
2 \sigma(I)]\end{array}$ & 2507 & 2538 \\
\hline Parameters & 177 & 183 \\
\hline Restraints & 1 & 0 \\
\hline$F(000)$ & 644 & 1416 \\
\hline$R_{\text {int }}$ & 0.0296 & 0.0383 \\
\hline Goodness of fit on $F^{2}$ & 1.033 & 1.088 \\
\hline$R_{1}[I \geq 2 \sigma(I)]$ & 0.0296 & 0.0400 \\
\hline$w R_{2}[I \geq 2 \sigma(I)]$ & 0.0697 & 0.1014 \\
\hline$R_{1}$ (all data) & 0.0348 & 0.0554 \\
\hline$w R_{2}$ (all data) & 0.0716 & 0.1136 \\
\hline $\begin{array}{l}\text { Largest diff. Peak and hole } \\
\left(\mathrm{e} \AA^{-3}\right)\end{array}$ & $0.435,-0.277$ & $0.600,-0.561$ \\
\hline
\end{tabular}

Table 2 Selected bond lengths $/ \AA$ and angles $/{ }^{\circ}$ for the complexes.

\begin{tabular}{|c|c|c|c|}
\hline & \multicolumn{2}{|c|}{ (1) } & \\
\hline $\mathrm{Cu} 1-\mathrm{O} 1$ & $1.913(2)$ & Cu1-N1 & $1.940(2)$ \\
\hline Cu1-N2 & $2.049(2)$ & Cu1-N3 & $1.976(2)$ \\
\hline Cu1-N5A & $2.545(2)$ & & \\
\hline O1-Cu1-N1 & 93.3(1) & O1-Cu1-N3 & $90.9(1)$ \\
\hline N1-Cu1-N3 & $161.2(1)$ & O1-Cu1-N2 & $176.8(1)$ \\
\hline N1-Cu1-N2 & $84.4(1)$ & N3-Cu1-N2 & 92.1(1) \\
\hline O1-Cu1-N5A & $87.8(1)$ & N1-Cu1-N5A & $94.1(1)$ \\
\hline N2-Cu1-N5A & $90.2(1)$ & N3-Cu1-N5A & $104.4(1)$ \\
\hline \multicolumn{4}{|c|}{ Symmetry code for A: $1-x, 1 / 2+y, 1 / 2-z$} \\
\hline & \multicolumn{2}{|c|}{$(2)$} & \\
\hline $\mathrm{Cu} 1-\mathrm{O} 1$ & $1.935(2)$ & Cu1-N1 & $1.994(2)$ \\
\hline Cu1-N2 & $2.106(2)$ & Cu1-N3 & $2.011(3)$ \\
\hline Cu1-N5A & $2.380(3)$ & & \\
\hline O1-Cu1-N1 & $89.4(1)$ & O1-Cu1-N3 & $87.2(1)$ \\
\hline N1-Cu1-N3 & $162.8(1)$ & O1-Cu1-N2 & $172.2(1)$ \\
\hline N1-Cu1-N2 & $93.0(1)$ & N3-Cu1-N2 & $88.3(1)$ \\
\hline O1-Cu1-N5A & $96.9(1)$ & N1-Cu1-N5A & $94.7(1)$ \\
\hline N3-Cu1-N5A & $102.5(1)$ & N2-Cu1-N5A & $90.3(1)$ \\
\hline \multicolumn{4}{|c|}{ Symmetry code for A: $1 / 2+x, y, 1 / 2-z$} \\
\hline
\end{tabular}

\section{RESULTS AND DISCUSSION}

The Schiff bases $\mathrm{HL}^{1}$ and $\mathrm{HL}^{2}$ were readily prepared by the condensation reaction of 4-methoxysalicylaldehyde with $N$-methylethane-1,2-diamine, and 5-chlorosalicylaldehyde with $N, N$-dimethylpropane-1,3-diamine, respectively, in methanol. The copper complexes were prepared by the reaction of the Schiff bases, copper nitrate, and sodium azide in methanol under room temperature. The oily product of the Schiff bases and crystalline product of the complexes are stable in air, and soluble in common polar organic solvents such as DMSO, DMF, methanol, ethanol, and acetonitrile, but insoluble in water. The molar conductance values for complexes $\mathbf{1}$ and $\mathbf{2}$ measured in methanol at a concentration of $10^{-3} \mathrm{M}$ are 21 and $25 \Omega^{-1} \mathrm{~cm}^{2} \mathrm{~mol}^{-1}$, respectively, suggesting they are non-electrolytes ${ }^{19}$.

Structural Description of the Complexes: The molecular structures of complexes (1) and (2) are shown in Figs. 1 and 2, respectively. X-ray crystallography reveals that both complexes are end-to-end azido-bridged polymeric copper(II) species. The $\mathrm{Cu} \cdots \mathrm{Cu}$ distances are 5.173(2) $\AA$ in (1) and 5.277(2) $\AA$ in (2). Both Schiff bases serve as tridentate ligands to form five- and six-membered chelate rings with $\mathrm{Cu}$ atom in the complexes. The coordination geometry around each metal center can be best described as a slight distorted square pyramid, with the three donor atoms of the Schiff base ligand and one azido $\mathrm{N}$ atom defining the basal plane, and with another azido $\mathrm{N}$ atom occupying the apical position. The $\mathrm{Cu}$ atoms in the complexes lie 0.142(2) $\AA$ for (1) and 0.210(2) $\AA$ for (2) from the least-squares planes defined by the basal donor atoms, in the direction of the apical ligands. The coordinate bond distances and bond angles in (1) are shorter than those in (2), which might caused by the existence of five-membered chelate ring Cu1-N1$\mathrm{C} 8-\mathrm{C} 9-\mathrm{N} 2$ in (1), while six-membered chelate ring Cu1-N1-C8-C9-C10-N2 in (2). When compared to other similar complexes ${ }^{15,20-23}$, it can be seen that the bond differences are not unusual.

In the crystal structure of complex (1), $\left[\mathrm{CuL}^{1}\right]$ units are linked through end-to-end azido bridges, as well as intermolecular $\mathrm{N}-\mathrm{H} \cdots \mathrm{O}$ and $\mathrm{C}-\mathrm{H} \cdots \mathrm{N}$ hydrogen bonds (Table 3), to form chains running along $b$ axis (Fig. 3). In the crystal structure of complex (2), [CuL $\left.{ }^{2}\right]$ units are linked through end-to-end azido bridges, as well as intermolecular $\mathrm{C}-\mathrm{H} \cdots \mathrm{N}$ hydrogen bonds (Table 3 ), to form chains running along $a$ axis (Fig. 4).

Table 3 Hydrogen-bond geometry $\left(\AA,^{\circ}\right)$ of the complexes.

\begin{tabular}{|c|c|c|c|c|}
\hline$D-\mathrm{H} \cdots A$ & $\begin{array}{c}d(D-\mathrm{H}) \\
(\AA)\end{array}$ & $\begin{array}{c}d(\mathrm{H} \cdots A) \\
(\AA)\end{array}$ & $\begin{array}{c}d(D \cdots A) \\
(\AA)\end{array}$ & $\begin{array}{c}\text { Angle }(D- \\
\mathrm{H} \cdots A)\left({ }^{\circ}\right)\end{array}$ \\
\hline$(1)$ & & & & \\
\hline $\mathrm{N} 2-\mathrm{H} 2 \cdots \mathrm{O} 1^{\mathrm{i}}$ & $0.90(1)$ & $2.29(1)$ & $3.192(3)$ & $178(4)$ \\
\hline $\mathrm{C} 9-\mathrm{H} 9 \mathrm{~A} \cdots \mathrm{N} 3^{\mathrm{i}}$ & 0.97 & $2.59(1)$ & $3.445(3)$ & $146(4)$ \\
\hline $\mathrm{C} 10-\mathrm{H} 10 \mathrm{~B} \cdots \mathrm{N} 3$ & 0.96 & $2.56(1)$ & $3.081(3)$ & $114(4)$ \\
\hline$(2)$ & & & & \\
\hline $\mathrm{C} 8-\mathrm{H} 8 \mathrm{~B} \cdots \mathrm{N} 3^{\mathrm{ii}}$ & 0.97 & $2.59(1)$ & $3.557(3)$ & $176(4)$ \\
\hline $\mathrm{C} 12-\mathrm{H} 12 \mathrm{~B} \cdots \mathrm{N} 3$ & 0.96 & $2.37(1)$ & $2.919(3)$ & $116(4)$ \\
\hline
\end{tabular}

Symmetry codes: (i) $1-x, 1 / 2+y, 1 / 2-z$; (ii) $1 / 2-x,-1 / 2+y, z$.

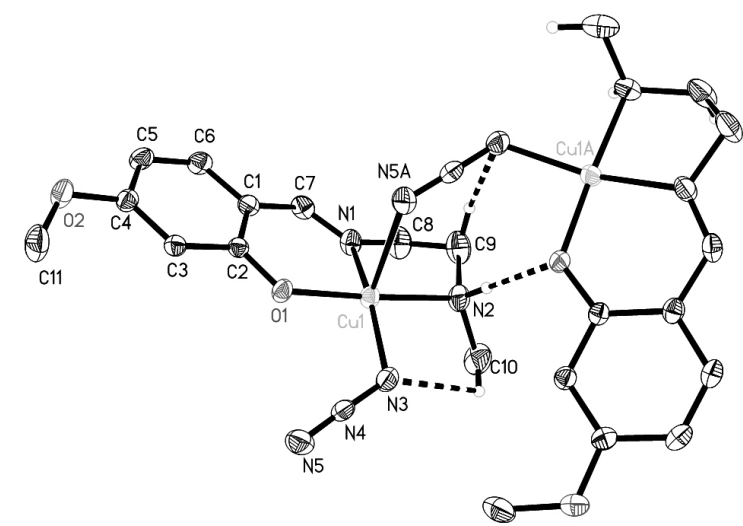

Fig. 1 A perspective view of the asymmetric unit of complex (1). Thermal ellipsoids are drawn at the $30 \%$ probability level. Hydrogen bonds are shown as dashed lines. 


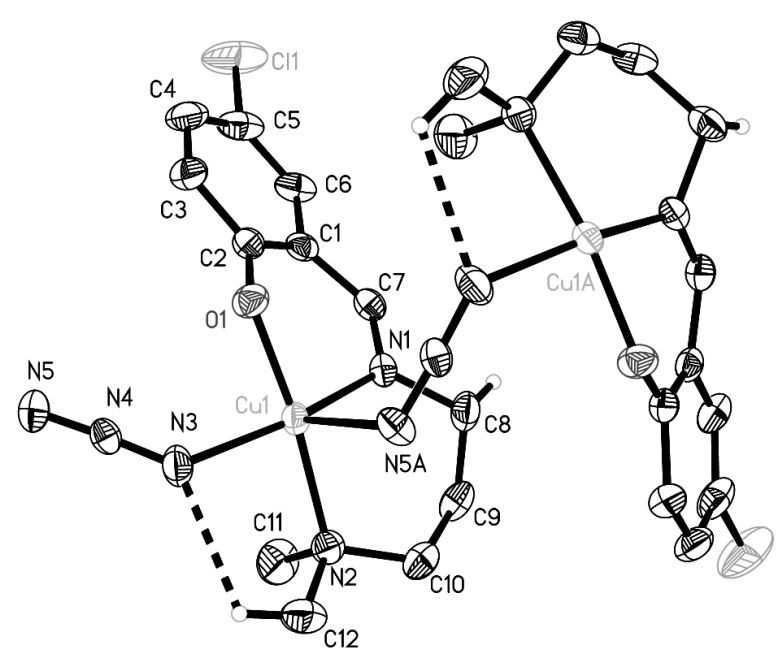

Fig. 2 A perspective view of the asymmetric unit of complex (2). Thermal ellipsoids are drawn at the $30 \%$ probability level. Hydrogen bonds are shown as dashed lines.

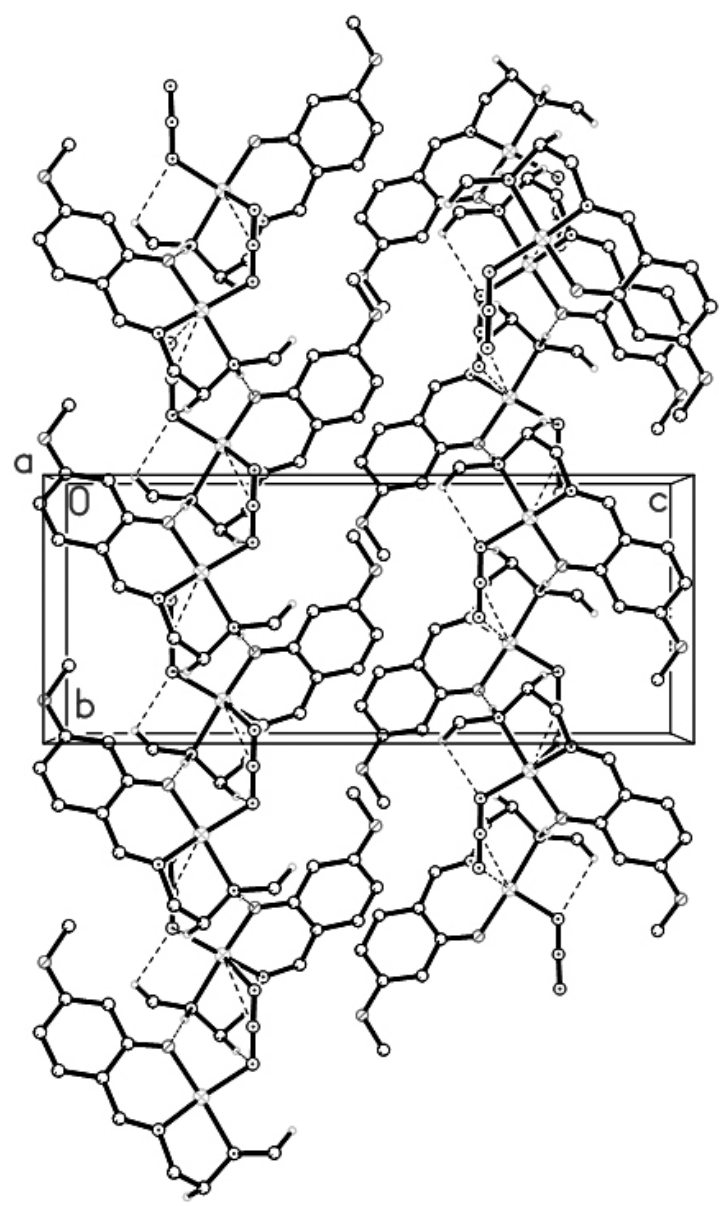

Fig. 3 Molecular packing of complex (1), viewed along the $a$ axis. Hydrogen bonds are shown as thin dashed lines.

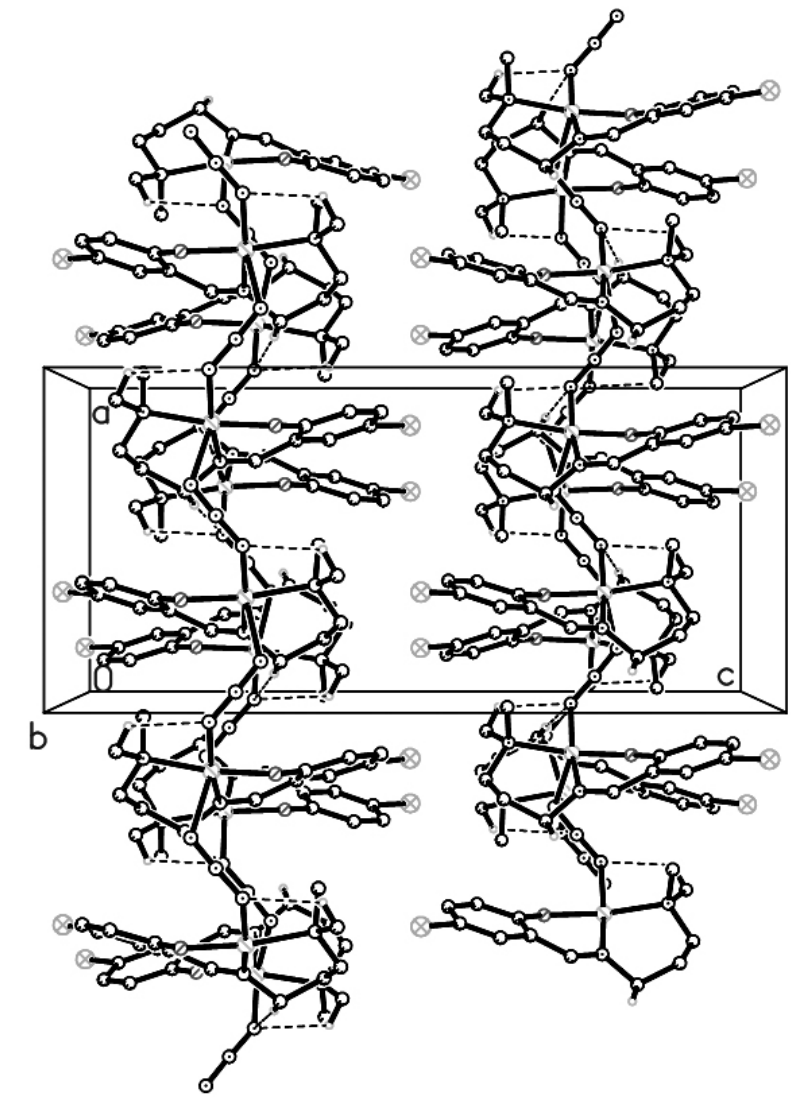

Fig. 4 Molecular packing of complex (2), viewed along the $b$ axis. Hydrogen bonds are shown as thin dashed lines.

IR spectra: The IR spectra of the Schiff bases and their complexes provide information about the metal-ligand bonding. The weak and broad absorptions in the region $3250-3400 \mathrm{~cm}^{-1}$ are assigned to the $\mathrm{O}-\mathrm{H}$ groups of the free Schiff bases. In the spectrum of complex (2), the weak and sharp band at $3207 \mathrm{~cm}^{-1}$ is assigned to the vibration of $\mathrm{N}-\mathrm{H}$ group. The strong absorption bands at 1615 $\mathrm{cm}^{-1}$ for $\mathrm{HL}^{1}$ and $1618 \mathrm{~cm}^{-1}$ for $\mathrm{HL}^{2}$ are assigned to the azomethine groups, $v(\mathrm{C}=\mathrm{N})^{24}$. These bands are shifted to lower wave numbers in the spectra of the complexes (1601 cm-1 for (1) and $1603 \mathrm{~cm}^{-1}$ for (2)), attributed to coordination of the azomethine nitrogen atoms to the metal atoms. The strong absorption bands of the Ar-O bonds for the free Schiff bases are located at about 1239 $\mathrm{cm}^{-1}$, which are observed at lower wave numbers for the complexes $\left(1219 \mathrm{~cm}^{-1}\right.$ for (1) and $1216 \mathrm{~cm}^{-1}$ for (2)). The intense bands indicative of the azide ligands are located at $2036 \mathrm{~cm}^{-1}$ for (1) and $2045 \mathrm{~cm}^{-1}$ for $(2)^{25}$. Weak absorption bands indicative of the $\mathrm{Cu}-\mathrm{O}$ and $\mathrm{Cu}-\mathrm{N}$ bonds are observed in the region $300-650$ $\mathrm{cm}^{-1}$.

\section{CONCLUSION}

In summary, we have reported the self-assembly preparation, crystal structures, and characterization of two new end-to-end azido-bridged polymeric copper(II) complexes derived from the tridentate Schiff bases 5-methoxy-2-[(2-methylaminoethylimino)methyl]phenol and 4-chloro-2[(3-dimethylaminopropylimino)methyl]phenol. The results revealed that the hydrogen bonds may influence the bridging modes of the azido ligands. More work needs to be carried out to investigate the influence factors, such as solvent and temperature used for the crystallization, steric effects of the ligands, as well as the molar ratio of the starting materials.

Appendix A. Supplementary data

CCDC - 891221 for (1) and 914978 for (2) contain the supplementary crystallographic data for this paper. These data can be obtained free of charge at http://www.ccdc.cam.ac.uk/const/retrieving.html or from the Cambridge Crystallographic Data Centre (CCDC), 12 Union Road, Cambridge CB2 1EZ, UK; fax: +44(0)1223-336033 or e-mail: deposit@ccdc.cam.ac.uk. 


\section{REFERENCES}

1. S.S. Massoud, R. Vicente, P.R. Fontenot, A.A. Gallo, M. Mikuriya, J.H. Albering, F.A. Mautner, Polyhedron 46, 66, (2012).

2. L.-L. Ni, Z.-L. You, L. Zhang, C. Wang, K. Li, Transition Met. Chem. 35, 13, (2010).

3. Z.-L. You, Y. Lu, N. Zhang, B.-W. Ding, H. Sun, P. Hou, C. Wang, Polyhedron 30, 2186, (2011)

4. F.A. Mautner, J.H. Albering, M. Mikuriya, S.S. Massoud, Inorg. Chem. 13, 796, (2010)

5. G. Andreev, N. Budantseva, A. Fedoseev, P. Moisy, Inorg. Chem. 22, 11481, (2011).

6. K.S. Banu, S. Mondal, A. Guha, S. Das, T. Chattopadhyay, E. Suresh, E. Zangrando, D. Das, Polyhedron 30, 163, (2011).

7. A. Das, S. Demeshko, S. Dechert, F. Meyer, Eur. J. Inorg. Chem. 8, 1240, (2011).

8. F.-C. Liu, J.-P. Zhao, B.-W. Hu, Y.-F. Zeng, J. Ribas, X.-H. Bu, Dalton Trans. 39, 1185, (2010).

9. Q.-L. Wang, X.-Q. Jia, D.-Z. Liao, S.-P. Yan, P. Cheng, G.-M. Yang, H.X. Ren, Z.-H. Jiang, Transition Met. Chem. 31, 434, (2006).

10. C. Aronica, E. Jeanneau, H. El Moll, D. Luneau, B. Gillon, A. Goujon, A. Cousson, M.A. Carvajal, V. Robert, Chem. Eur. J. 13, 3666, (2007).

11. A.M. Talarico, E.I. Szerb, T.F. Mastropietro, I. Aiello, A. Crispini, M. Ghedini, Dalton Trans. 41, 4919, (2012).

12. R.A. Taylor, D.J. Law, G.J. Sunley, A.J.P. White, G.J.P. Britovsek, Chem. Commun. 24, 2800, (2008).
13. E.C. Constable, G.Q. Zhang, C.E. Housecroft, M. Neuburger, J.A. Zampese, Chem. Commun. 46, 3077, (2010).

14. J.-C. Zhang, X.-S. Zhou, X.-L. Wang, X.-F. Li, Z.-L. You, Transition Met. Chem. 36, 93, (2011)

15. G. Zakrzewski, L. Sacconi, Inorg. Chem. 7, 1034, (1968).

16. Bruker, SMART and SAINT, Bruker AXS Inc., Madison, Wisconsin, USA, (1998).

17. G.M. Sheldrick, SADABS Program for Empirical Absorption Correction of Area Detector, University of Göttingen, Germany, (1996).

18. G.M. Sheldrick, SHELXTL V5.1 Software Reference Manual, Bruker AXS, Inc., Madison, Wisconsin, USA, (1997).

19. W.J. Geary, Coord. Chem. Rev. 7, 81, (1971).

20. D.-M. Xian, Z.-L. You, M. Zhang, P. Hou, X.-H. Li, J. Coord. Chem. 64, 3265, (2011).

21. Z.-L. You, L. Zhang, D.-H. Shi, X.-L. Wang, X.-F. Li, Y.-P. Ma, Inorg. Chem. Commun. 13, 996, (2010).

22. L.-L. Ni, Z.-L. You, L. Zhang, C. Wang, K. Li, Transition Met. Chem. 35, 13, (2010)

23. C. Adhikary, D. Mal, K. Okamoto, S. Chaudhuri, S. Koner, Polyhedron 25, 2191, (2006).

24. Y.-M. Zhou, X.-R. Ye, F.-B. Xin, X.-Q. Xin, Transition Met. Chem. 24, $118,(1999)$.

25. S. Chattopadhyay, M.S. Ray, M.G.B. Drew, A. Figuerola, C. Diaz, A. Ghosh, Polyhedron 25, 2241, (2006). 